PAPER

CrossMark

\title{
Comparision of in situ spectroscopic ellipsometer and ex situ x-ray photoelectron spectroscopy depth profiling analysis of $\mathrm{HfO}_{2} / \mathrm{Hf} / \mathrm{Si}$ multilayer structure
}

26 February 2018

REVISED

29 July 2018

ACCEPTED FOR PUBLICATION

6 August 2018

PUBLISHED

17 August 2018

\author{
Ayten Cantas $^{1,2,3}$ (D), Lutfi Ozyuzer ${ }^{1}$ and Gulnur Aygun $^{1}$ (D) \\ 1 Department of Physics, Izmir Institute of Technology, Urla, 35430, Izmir, Turkey \\ 2 Department of Electric and Energy, Pamukkale University, 20160, Denizli, Turkey \\ 3 Author to whom any correspondence should be addressed \\ E-mail: aytencantas@iyte.edu.tr and abagdas@pau.edu.tr
}

Keywords: $\mathrm{HfO}_{2}$, reactive rf sputtering, SE, XPS, FTIR, high- $k$ dielectric material

\begin{abstract}
$\mathrm{A} \mathrm{HfO}_{2}$ film was grown by RF magnetron sputtering technique on a Si substrate Using in situ Spectroscopic Ellipsometry (SE), the film thickness and refractive index were examined as a function of deposition time. Ex situ x-ray Photoelectron Spectroscopy (XPS) was used in depth profile mode to determine the phase evolution of $\mathrm{HfO}_{2} / \mathrm{Hf} / \mathrm{Si}$ multilayer structure after the growth process. The chemical composition and the crystal structure of the film were investigated by Fourier Transform Infrared (FTIR) spectroscopic measurements and x-ray Diffraction in Grazing Incidence (GI-XRD) mode, respectively. The results showed that the film was grown in the form of $\mathrm{HfO}_{2}$ film. According to $\mathrm{SE}$ analysis, reactive deposition of $\mathrm{HfO}_{2}$ directly on $\mathrm{Hf} / \mathrm{Si}$ results to $\mathrm{SiO}_{2}$ interface of about $2 \mathrm{~nm}$. The final $\mathrm{HfO}_{2}$ films thickness is $5.4 \mathrm{~nm}$. After a certain period of time, the XPS depth profile revealed that the film was in the form of $\mathrm{Hf}$-rich $\mathrm{Hf}$ silicate with $\mathrm{SiO}_{2}$ interfacial layer. In reference to XPS quantification analysis from top to bottom of film, the atomic concentration of $\mathrm{Hf}$ element reduces from $19.35 \%$ to $7.13 \%$, whereas $\mathrm{Si}$ concentration increases from $22.99 \%$ to $74.89 \%$. The phase change of $\mathrm{HfO}_{2}$ film with time is discussed in details.
\end{abstract}

\section{Introduction}

Nowadays, the silicon oxide $\left(\mathrm{SiO}_{2}\right)$ and the related nitrides such as silicon nitride $\left(\mathrm{Si}_{3} \mathrm{~N}_{4}\right)$ and silicon oxynitride $\left(\mathrm{SiO}_{\mathrm{x}} \mathrm{N}_{\mathrm{y}}\right)$ have thickness limitations [1]. While the size of the Metal-Oxide-Semiconductor (MOS) devices are scaling down, being smaller than $2 \mathrm{~nm}$, the gate dielectric, made of $\mathrm{SiO}_{2}$ and the related nitrides, results in an unacceptable leakage current. Therefore, there is an increasing interest in microelectronics to obtain the same effective capacitance with oxides having a higher dielectric constant, $\kappa$, and a physically thicker layer than Si for their usage as the gate insulator [2]. There are many additional requirements for these oxides. For example, they must have a high thermodynamic stability in order not to react with Si. Also, their diffusion coefficients should be low in order to withstand the process temperature. To have a low leakage current, the oxide should be treated by wide band-gap semiconductors. Properties of thin oxide films on silicon vary widely in terms of their general and interfacial morphologies. Gate oxides should also form high quality interfaces with silicon having low interfacial defects and roughnesses for the needs of electronic device quality. Otherwise, it results in a carrier mobility degradation in the MOS structure. Thus, it is very crucial to study an encouraging prospective material to replace the $\mathrm{Si}$ based gate oxides. In that respect, $\mathrm{HfO}_{2}$ is a favorite high- $k$ material [3-6] to be studied for the development of MOS devices because of its wide band gap $\left(\mathrm{E}_{\mathrm{g}}>5 \mathrm{eV}\right)$ [7], a high- $\kappa$ dielectric constant $(\kappa=25)$ [8] and thermal stability on $\mathrm{Si}$ [9].

The aim of this study was to investigate the chemical evolution of $\mathrm{HfO}_{2}$ films during and after the growth process. Thin $\mathrm{HfO}_{2}$ film was grown on $\mathrm{Hf} / \mathrm{Si}$ wafer by rf magnetron sputtering technique. In-situ Spectroscopic Ellipsometry (SE) port-mounted onto magnetron sputtering system was used to systematically investigate phase 
variation of $\mathrm{HfO}_{2}$ film and its interface with $\mathrm{Si}$ substrate. Thickness and optical properties of $\mathrm{HfO}_{2}$ film was determined as a function of deposition time. After the deposition, the chemical form of $\mathrm{HfO}_{2}$ film and its interface were searched by $\mathrm{x}$-ray Photoelectron Spectroscopy (XPS) in depth profile mode. This paper intents to shine light on the chemical structure variation of $\mathrm{HfO}_{2}$ film during and after the deposition. Although the $\mathrm{HfO}_{2}$ film and its interface with Si substrate have been discussed in literature by XPS [10-13], this is the first study, to our knowledge, which allows to cross-check the results of in situ Spectroscopic Ellipsometry (SE) and X-ray Photoelectron Spectroscopy (XPS) depth profile analysis.

\section{Experimental details}

An $n$-type $\langle 100\rangle$ crystalline silicon (c-Si) wafer with a 5-8 $\Omega$.cm resistivity, a 256 to $306 \mu \mathrm{m}$ thickness, and a $50.8 \pm 0.5 \mathrm{~mm}$ diameter was used as a substrate. The $\mathrm{HfO}_{2}$ film was prepared by RF magnetron sputtering technique employing a high purity $\mathrm{Hf}$ target with 2 a inch diameter, a 0.25 inch thickness, and a 99.9\% purity. The schematic representation of our magnetron sputtering system coupled with an in situ SE system was given in a previous study [14].

Before the $\mathrm{HfO}_{2}$ film deposition, the thickness calibration of a $\mathrm{Hf}$ metal film was done by growing it on a soda lime glass (SLG) substrate. By means of SE, the determination of thickness and the characterization of the optical properties of metals have been rather difficult than oxide dielectric layers. Optical properties of metals vary according to deposition methods and process conditions and also they are sensitive to surface oxidation and surface roughness due to very small penetration depths of light in metals. Since the optical properties of metals show significant thickness dependences particularly when the thickness of metals is very thin $(<10 \mathrm{~nm})$ [15], Hf metal layer was not added to the model during the fitting process of SE measurement. As a result, thickness calibration of $\mathrm{Hf}$ metallic buffer film was done by growing it on a soda lime glass (SLG) substrate by magnetron sputtering technique. The growth rate of the Hf film was determined to be $5 \mathrm{~nm} \mathrm{~min}^{-1}$ by a Veeco DEKTAK 150 surface profilometer. Before deposition, the Si substrate was cleaned for $30 \mathrm{~s}$ in a $1 \%$ diluted HydroFluoric (HF) acid solution with a 1/100 ratio of HF to de-ionized water in order to remove the native oxide. Then, it was rinsed in de-ionized water, dried with pure nitrogen gas and quickly placed on the substrate holder inside the deposition chamber of our RF magnetron sputtering system, which has a $7.6 \mathrm{~cm}$ distance to the target. The chamber was first evacuated down to a pressure below $10^{-6}$ Torr, then, an argon gas was sent into the deposition chamber. During the sputtering, the working pressure was $0.44 \times 10^{-3}$ Torr. The film was grown under $30 \mathrm{~W}$ $\mathrm{RF}$ power and $0.4 \mathrm{O}_{2} / \mathrm{Ar}$ gas ratio. Before starting the deposition, when the shutter was close and plasma occurred, it was waited for about $60 \mathrm{~s}$ for the RF voltage to remain constant. Apart from that, it was not spent an extra time for the $\mathrm{Hf}$ target cleaning. Prior to 3 min reactive $\mathrm{HfO}_{2}$ film growth, a thin $\mathrm{Hf}$ metal was deposited for 60 s onto the $\mathrm{Si}$ substrate on purpose. The thicknesses of the $\mathrm{HfO}_{2}$ film and the $\mathrm{SiO}_{2}$ interface layer were examined by a SENTECH SE-801 Spectroscopic Ellipsometer (SE) which was mounted onto the magnetron sputtering system. For the in situ SE measurements, the wavelength and the angle of incidence for the probing light were $632 \mathrm{~nm}$ and $70^{\circ}$, respectively. The in situ SE, ellipsometric measurements for the amplitude ratio, $\Psi$, and the phase difference, $\Delta$, between the incident and the reflected light, were taken with $20 \mathrm{~s}$ time intervals during the film growth. Before the deposition, a single initial measurement was made to determine the $\mathrm{SiO}_{2}$ native oxide. After that, the $\mathrm{Hf}$ metallic layer was purposely deposited on the Si substrate for $60 \mathrm{~s}$. Then, $\mathrm{HfO}_{2}$ film was deposited via reactive oxidation process for $3 \mathrm{~min}$. After the oxidation, to determine the existing phases, measurements of $\Psi$ and $\Delta$ were continued. The thickness $(d)$ and the refractive index $(n)$ values of both the $\mathrm{HfO}_{2}$ film and the $\mathrm{SiO}_{2}$ interface layer were determined from the in situ ellipsometric data obtained as described above. To extract these optical parameters, a convenient ellipsometry model is needed for the thin film stack. As a result, an appropriate optical model was constructed for our $(\Psi, \Delta)$ ellipsometric data for the fitting. Our film stack was composed of three layers on $\mathrm{Si}$ substrate, i.e., Air $/ \mathrm{HfO}_{2} / \mathrm{SiO}_{2} / \mathrm{c}-\mathrm{Si}$ (from top to bottom in the respective order) [14]. As an optical model, the Cauchy dispersion relation which is a polynomial function, was used. The Cauchy model is widely used for dielectrics and semiconductors in spectral regions where they are transparent. Since the $\mathrm{HfO}_{2}$ thin film and the $\mathrm{SiO}_{2}$ interfacial layer are transparent to the light used in the spectral range of interest, i.e. $\lambda>350 \mathrm{~nm}$, the Cauchy dispersion relation was used for the fitted range from 300 to $850 \mathrm{~nm}$. In the fitting process; to obtain a similar graph between modelled and measured ellipsometric data $(\Psi, \Delta)$, the first suitable guesses were made for the thicknesses of the $\mathrm{HfO}_{2}$ film and the $\mathrm{SiO}_{2}$ interfacial layer. And then, $\Psi$ and $\Delta$ for these first guesses were fitted for comparison with the experimental counterparts. The thickness and refractive index of $\mathrm{HfO}_{2}$ thin high-k layer as well as the thickness of $\mathrm{SiO}_{2}$ interfacial layer were used as the fitting parameters. The details of the theoretical model used for the analysis of the SE data were given in the literature [14].

The crystal structure of the film was investigated by a thin film x-ray Diffraction (XRD) system (Panalytical X' Pert Pro MRD) using the $\mathrm{Cu} K_{\alpha}$ line with a wavelength of $1.5402 \AA$, a step size of $0.03^{\circ}$, and a step time of $0.6 \mathrm{~s}$ 
in the grazing incidence mode. The XRD patterns were analyzed by means of X'pert High Score computer software including ICDD database including the diffraction patterns of many known structures.

The chemical composition of the film and its interface with Si were analyzed by a Fourier Transform Infrared (FTIR) spectrometer (BRUKER Equinox 55) in the spectral range of 400-1200 $\mathrm{cm}^{-1}$. The depth profile analysis was performed by x-ray Photoelectron Spectroscopy (XPS) (Phoibos $1503 \mathrm{D}$-DLD). A Mg source with a $\mathrm{K}_{\alpha}$ radiation was used as the $\mathrm{x}$-ray source (with $\mathrm{h} \nu=1254 \mathrm{eV}$ ) operating at a $249 \mathrm{~W}$ power. Before the XRD measurements, the $\mathrm{HfO}_{2}$ film was etched for 17 etching cycles, during each cycle a $1 \mathrm{keV} \mathrm{Ar}{ }^{+}$ion beam was incident on the film for $2 \mathrm{~min}$. The analyzer pass energy was set to $96 \mathrm{eV}$. Since the film surface had carbon contamination which might affect the peak fitting process, the surface layer has been eliminated. For all 17 layers (one for each etching cycle) the $\mathrm{Si} 2 p(99.3 \mathrm{eV}$ ) peak was used for energy calibration of the peaks for the XPS analyses. After a Shirley background subtraction, the deconvolution process of the spectra was achieved with peak type of Gaussian-Lorentzian product function by using the CasaXPS software [16-18].

\section{Results and discussions}

\subsection{Spectroscopic ellipsometer measurements}

SE with $70^{\circ}$ incidence angle of light was used to obtain the thickness and the optical constants of the $\mathrm{HfO}_{2}$ film as a function of sputter time. The ellipsometric measurements $(\Psi, \Delta)$ were simulated according to Air $/ \mathrm{HfO}_{2} / \mathrm{SiO}_{2} / \mathrm{c}$-Si three layer model. The thickness $d$ and the refractive index $n$ of film were determined in terms of a regression analysis approach. The Marquardt-Levenberg algorithm was used as for the fitting algorithm. This algorithm determines the model which minimizes the difference between the measured and the calculated ellipsometric data $(\Psi, \Delta)$. The mean-squared error (MSE) function was used to quantify the quality of fit. The details of the MSE function was given in our previous work [14]. The value of MSE which is closest to zero represents a perfect accuracy between the measured data and the calculated fit [14]. However, the minimum MSE value cannot be zero in practice because the number of free parameters in the analysis is generally lower than the number of experimental parameters affecting the data [15]. When MSE is much more than 1, the calculated spectra do not fit well to the experimental data. In our analyses a 'sufficiently good fitting' was obtained for MSE value which is 1.19. Since our MSE value is close to 1, we can say that the quality of the fit is indeed very good. Figures $1(\mathrm{a})$ and (b) represent the matching of measured and modeled ellipsometric values ( $\Psi$, $\Delta$ ) for the last measurement (taken at $400 \mathrm{~s}$ ) of the final film.

In figures 1(a) and (b), the modelled curve and the experimental data show some discrepancy near the band gap $(\sim 300 \mathrm{~nm})$ energy of $\mathrm{HfO}_{2}$. This situation is encountered already in the literature for $\mathrm{HfO}_{2}$ and $\mathrm{HfSiO}_{\mathrm{x}}$ film $[7,19]$. From the figure 1 , it can be clearly seen that a perfect agreement between the experimental data and the modeled curve has been achieved in the high wavelength range for the $\mathrm{HfO}_{2}$ films. However, the discrepancy is quite distinguishable for the low wavelength range. There might be several reasons for this discrepancy. Firstly, it might be caused by the spectral limitations of the instrument (300-850 nm) [19]. Secondly, it might be due to the optical properties of the film grown on the Si substrate which extremely affect the film quality [7]. Also the observed discrepancy near $300 \mathrm{~nm}$ wavelength might indicate the presence of a disorder within the $\mathrm{HfO}_{2}$ film $[7,19]$. As a result of our fitting process, the accuracies of the thickness calculation for both $\mathrm{HfO}_{2}$ and $\mathrm{SiO}_{2}$ layers were determined as 0.1 , whereas, the accuracy of the refractive index calculation for $\mathrm{HfO}_{2}$ was obtained as 0.001 . Figure 2 shows the thickness evolution of the growing film and the interface layer with respect to the deposition time. All these measurements were carried out simultaneously which allow us to evaluate the chemical structure of the film the deposition. The initial measurement (at $\mathrm{t}=0 \mathrm{~s}$, t being time) in figure 2 was taken just before the start of the deposition. Although $\mathrm{Si}$ substrate was cleaned before the film growth, the $2.4 \mathrm{~nm}$ thick native $\mathrm{SiO}_{2}$ was determined from the simulation of initial measurement. It is well known that $\mathrm{Si}$ is naturally oxidized in a very short time durations. Before the reactive oxidation was started, the Hf metal was first deposited (from $t=0$ and $\mathrm{t}=60 \mathrm{~s}$ ) on Si substrate. There are some reasons of deposition of $\mathrm{Hf}$ metal layer prior to growth of $\mathrm{HfO}_{2}$ film. Since Hf buffer layer can suppress the oxygen diffusion towards the $\mathrm{Si}$ substrate, the $\mathrm{SiO}_{2}$ formation can be minimized or eliminated by this way. Furthermore, $\mathrm{Hf}$ metal buffer layer can support the formation of $\mathrm{HfO}_{2}$ and $\mathrm{HfSiO}$ high-k dielectric layers by controlling the $\mathrm{O}$ diffusion. The other reason is that if the Si's native oxide happens under $\mathrm{Hf}$ metal, $\mathrm{Hf}$ metal can consume the oxygen of $\mathrm{SiO}_{2}$ to form $\mathrm{HfO}_{2}$ just leaving a Si-suboxide formation behind [10].

However, thickness of $\mathrm{HfO}_{2}$ as well as $\mathrm{SiO}_{2}$ showed a sudden increment during the $\mathrm{Hf}$ metal buffer layer deposition (in figure 2). Although there was not any intentional oxygen gas sent inside of the deposition chamber, there might be some other reasons for the observation of thickness increment in oxide formations of $\mathrm{Si}$ and Hf. If the pre-sputtering process of Hf target is not sufficient to eliminate the native oxide formation on the target surface, this oxide film from the target surface might be directly deposited on the substrate. This could be a possible reason for the determination of $\mathrm{HfO}_{2}$ thickness during the $\mathrm{Hf}$ deposition. In this case, thickness of $\mathrm{SiO}_{2}$ 

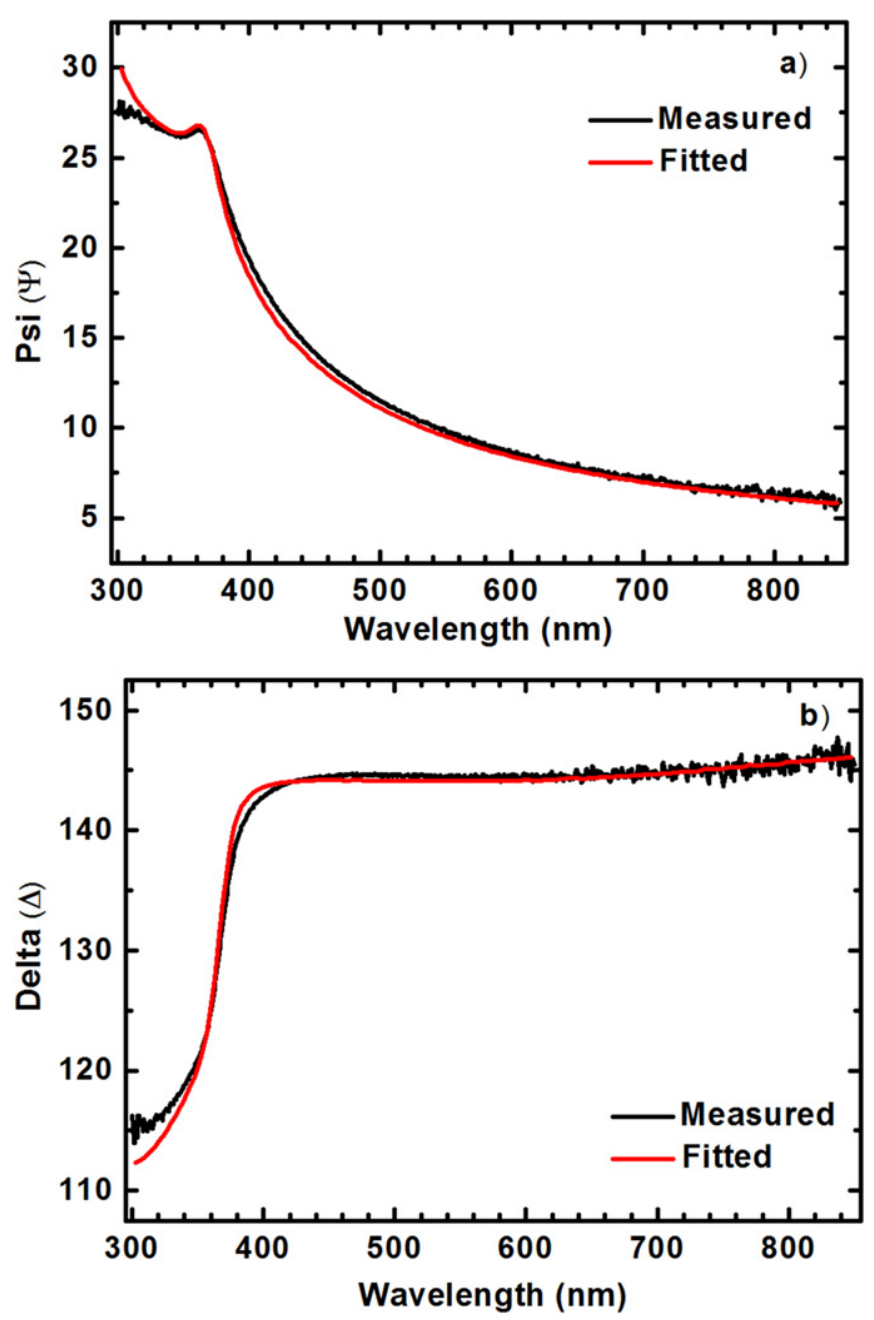

Figure 1. Fitting results of SE parameters for the last measurement of final film (a) $\Psi$ and (b) $\Delta$.

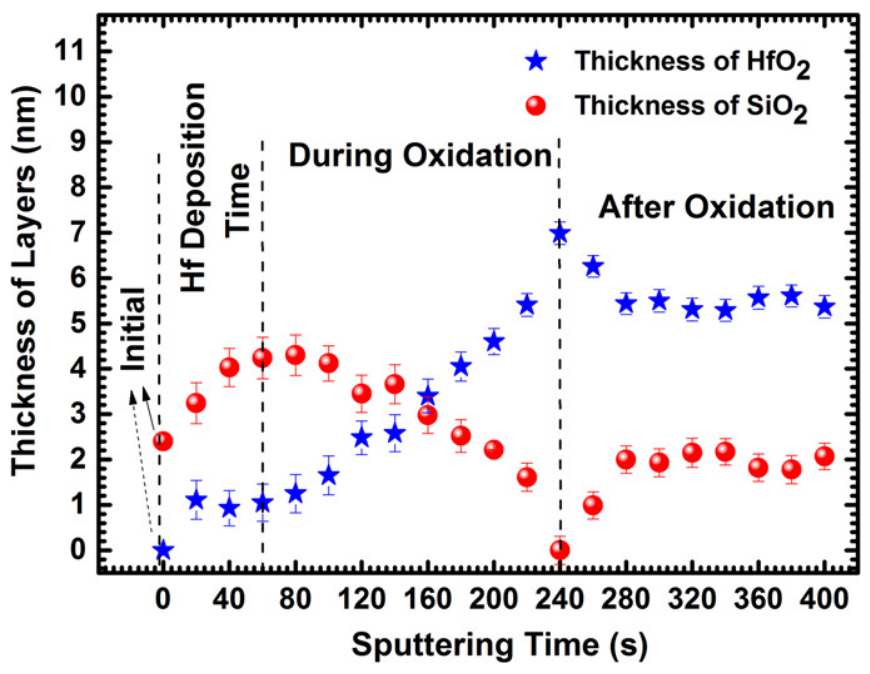

Figure 2. Thickness evolution of grown $\mathrm{HfO}_{2}$ film and $\mathrm{SiO}_{2}$ interface layer.

interface layer increases due to diffusion of $\mathrm{O}$ through the $\mathrm{HfO}_{2}$ film which oxidize the $\mathrm{Si}$ [8]. It is also possible that if Si's native oxide happens under $\mathrm{Hf}$ metal, $\mathrm{Hf}$ metal might consume the oxygen of $\mathrm{SiO}_{2}$ to form $\mathrm{HfO}_{2}$ just leaving a Si-suboxide formation behind [10]. 


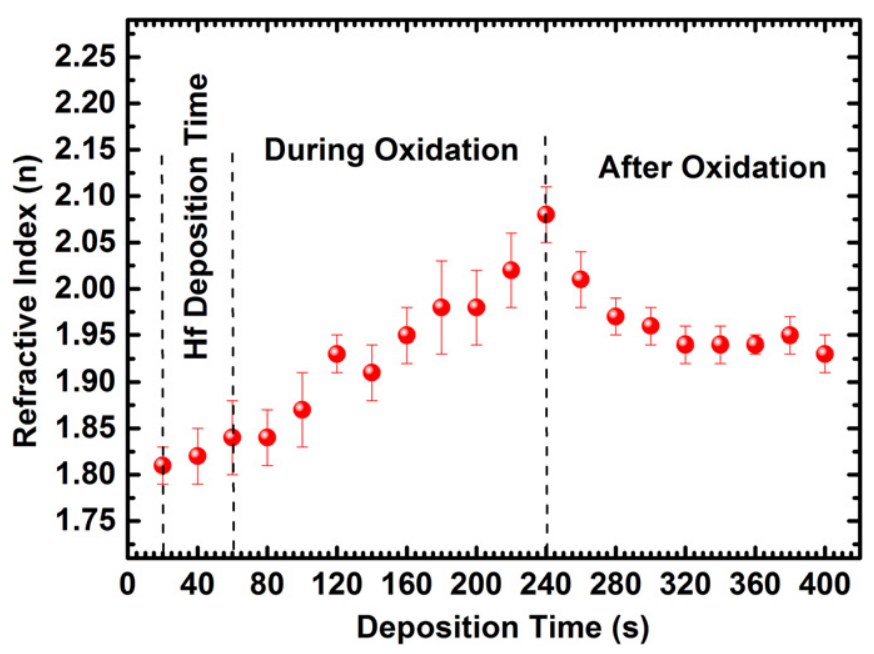

Figure 3. Refractive index of $\mathrm{HfO}_{2}$ as a function of deposition time at $632 \mathrm{~nm}$ wavelength.

During the reactively oxidation time, due to the oxygen affinity of $\mathrm{Hf}$ being higher than that of $\mathrm{Si}$, the thickness of $\mathrm{HfO}_{2}$ film increases linearly whereas that of the $\mathrm{SiO}_{2}$ layer decreases. The growth rate of $\mathrm{HfO}_{2}$ film in the chamber was $2 \mathrm{~nm} \mathrm{~min}{ }^{-1}$ at this time. After oxidation process, the thickness of $\mathrm{HfO}_{2}$ film decreased whereas that of the $\mathrm{SiO}_{2}$ layer started to increase. We think that, this is due to out diffusion of $\mathrm{Si}$ atoms into the grown film which result in a change in the chemical composition. After the thermal equilibrium was reached, $\mathrm{HfO}_{2}$ film and $\mathrm{SiO}_{2}$ interface thicknesses were stabilized at nearly $5.4 \mathrm{~nm}$ and $2 \mathrm{~nm}$, respectively, as obtained by our SE measurements taken with $632 \mathrm{~nm}$ wavelength. Figure 3 shows evolution of the refractive index of the $\mathrm{HfO}_{2}$ film. In the course of growth, the refractive index increased reaching to a maximum value of 2.07. After the oxidation process, it decreased down to 1.93 at thermal equilibrium. It is well known that the refractive index of a material is closely related to its packing density and polarization. During the reactively deposition the refractive index was increasing because the concentration of Hf, which has high polarization, in the film also increased. After the reactive oxidation, some chemical reactions inside the film might result the formation of porous structures and reduce the density of the grown film which caused the decrease in the refractive index. Because $\mathrm{Si}-\mathrm{O}$ bonds are less polar than the comparable $\mathrm{Hf}-\mathrm{O}$ bond, the refractive index reduces with the increase of the Si concentration in $\mathrm{HfO}_{2}$ film. In figure 3, after the oxidation the increase in Si concentration in the film which forms $\mathrm{HfSiO}$ structure resulted the decrement in the film polarization, then lower polarizability resulted in the reducing of the refractive index [20]. A second possibility for this decrease is that it can be due to reduction of thermal vibrations during the cooling which reduces the light scattering intensity from the thermal phonons.

$\mathrm{SE}$ results demonstrated that, $\mathrm{HfO}_{2}$ film was grown linear with a deposition time. During the reactive oxidation, natural $\mathrm{SiO}_{2}$ interface was disappeared due to the fact that $\mathrm{Hf}$ metal inside the system might consume the oxygen of $\mathrm{SiO}_{2}$ to form $\mathrm{HfO}_{2}$. After the reactive oxidation, $\mathrm{SiO}_{2}$ was started to appear due to diffusion of oxygen from $\mathrm{HfO}_{2}$ film to Si substrate. And the increase in the Si concentration in the $\mathrm{HfO}_{2}$ film due to the out diffusion of $\mathrm{Si}$ was caused the decrement in refractive index of $\mathrm{HfO}_{2}$ film.

\subsection{Structural properties by thin film XRD}

XRD measurement of the $\mathrm{HfO}_{2}$ film was performed using a $\mathrm{Cu} K_{\alpha}$ radiation at room temperature. Figure 4 shows the reflection planes of the $5.4 \mathrm{~nm}$ thick film where $2 \theta$ value of $51.5^{\circ}$ and $54.4^{\circ}$ were attributed to $(-221)$ and (202) monoclinic phase of $\mathrm{HfO}_{2}$, respectively, [21]. According to in situ $\mathrm{SE}$ analysis, the formation of $\mathrm{SiO}_{2}$ interface layer was observed. However, the presence of this phase was not detected by XRD. XRD measurement states the information related to the crystalline structure of the film under search just by giving peaks suitable to the crystalline structure of the underlying film. If the film is in amorphous structure other than crystalline, then no XRD peaks are realized in the measurement. Therefore, if the formed $\mathrm{SiO}_{2}$ was in amorphous structure, then it did not show peaks in XRD spectra. The grain size (crystallite size) of the $\mathrm{HfO}_{2}$ film was obtained by using Debye-Scherer formula with X'pert High Score software [22, 23]:

$$
\tau=\frac{K \lambda}{B \cos (\theta)}
$$

where $\mathrm{K}$ is a constant equal to $0.9, \lambda$ is the wavelength of $\mathrm{Cu} K_{\alpha}\left(1.54 \mathrm{~A}^{\circ}\right), B$ is defined as full width at half maximum intensity (FWHM), $\theta$ is the Bragg diffraction angle and $\tau$ is the mean size of the crystalline domains (size of the grain). Similarly, the lattice strain $\varepsilon$ of the film was calculated using a Debye-Scherer calculator in the 


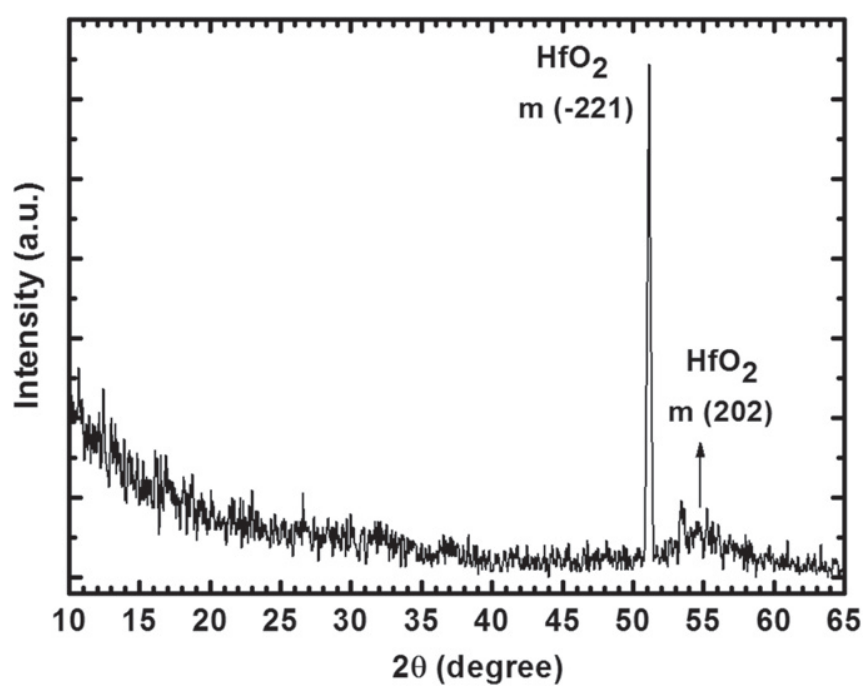

Figure 4. Grazing incidence mode of XRD pattern of $\mathrm{HfO}_{2}$ thin film.

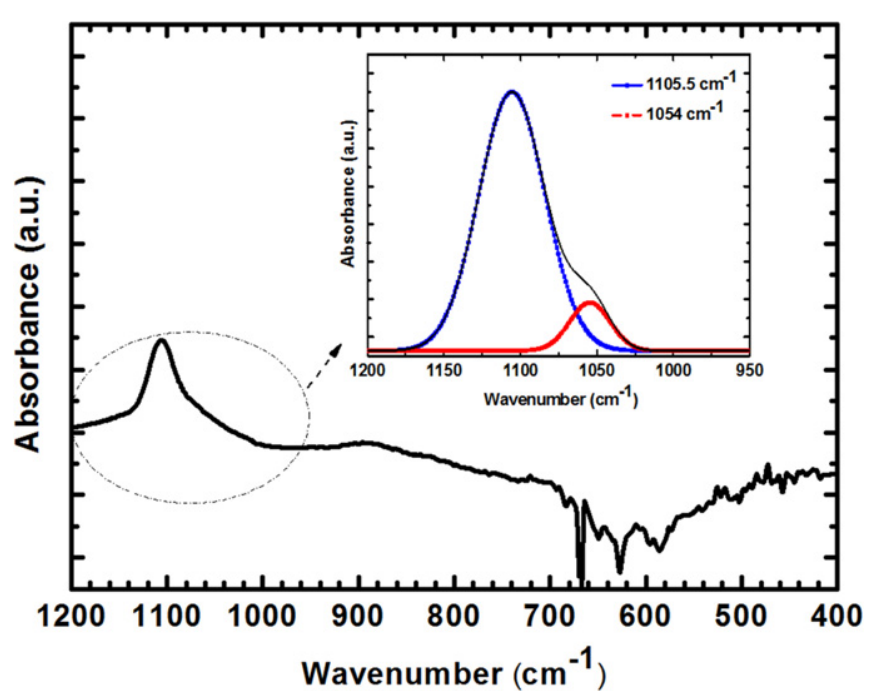

Figure 5. Absorption spectra of $\mathrm{HfO}_{2}$ film obtained from FTIR.

X'pert High Score software which employs the formula:

$$
\varepsilon=\frac{B}{4 \tan (\theta)}
$$

The grain size and the lattice strain of the diffraction peak for the (-221) orientation was obtained as $24.5 \mathrm{~nm}$ and $0.328 \%$, respectively. The reason that the calculated grain size of $\mathrm{HfO}_{2}$ is larger than the obtained total oxide thickness is the growth direction of grains. It is possible to observe greater grain sizes, for the laterally grown grains, than the total thickness of film $[24,25]$.

\subsection{FTIR spectra of RF sputtered $\mathrm{HfO}_{2}$ film}

The bonding structure of the $\mathrm{HfO}_{2}$ film was studied using the FTIR absorption spectrum of our sample taken in the range of 400-1200 $\mathrm{cm}^{-1}$. In figure 5 , several peaks observed between 512 and $600 \mathrm{~cm}^{-1}$ were associated with some vibrational modes of monoclinic $\mathrm{HfO}_{2}$ by D A Neumayer et al [26]. This association is in agreement with the XRD results for the film. The peak centered near at $670 \mathrm{~cm}^{-1}$ with a very low intensity results from the vibrations of a $\mathrm{C}-\mathrm{O}$ bond on or near the surface. This indicates a very small contamination of the surface with carbon. Hence, we can claim that the film surface is quite clean. The other peak centered at $610 \mathrm{~cm}^{-1}$ with a very low intensity is related to a $\mathrm{Si}-\mathrm{O}$ phonon mode which is caused by the formation of $\mathrm{SiO}_{\mathrm{x}}$ interface layer [27]. In the high wavenumber region, there occurs only one strong broad absorption band from 970.0 to $1150.0 \mathrm{~cm}^{-1}$. 
This observed band was de-convoluted into two Gaussian peaks centered at 1105.5 and $1054.0 \mathrm{~cm}^{-1}$ which were shown in the inset of figure 5 .

In literature $\mathrm{SiO}_{2}$ is reported to have a vibrational mode giving an absorption peak centered at $1075.0 \mathrm{~cm}^{-1}$. Hence, the deconvoluted peak centered at $1105.5 \mathrm{~cm}^{-1}$ cannot be due to $\mathrm{SiO}_{2}$. We think that this peak is a due to the existence of an asymmetric stretching vibration mode of $\mathrm{SiO}_{4}$ [28]. $\mathrm{The}_{\mathrm{SiO}}(\mathrm{x}<2)$ suboxide has vibrational modes producing absorption peaks in the region from 989.0 to $1057.0 \mathrm{~cm}^{-1}$ [14]. Hence, we can claim that, the peak located at $1054.0 \mathrm{~cm}^{-1}$ indicates the existence of a Si suboxide. As a result, FTIR analysis gave support for the in situ SE results in the presence of Si-based interface.

\subsection{XPS spectra of the $\mathrm{HfO}_{2}$ film}

\subsubsection{Si $2 \mathrm{p}$ depth profile}

Figure 6(a) shows all Si 2p emission signals of the photoelectron spectrum of the $\mathrm{HfO}_{2}$ film which is separated into two parts. The first part located at the lower binding energy side represents elemental Si whereas the second part at the higher binding energy side represents an oxide form of $\mathrm{Si} 2 p$ signal. It is well known that, the $\mathrm{Si} 2 p$ spectrum results from the contributions of five distinct structures including; (i) elemental $\mathrm{Si}\left(\mathrm{Si}^{0}\right)$, (ii) higher oxidation states $\mathrm{Si}_{2} \mathrm{O}\left(\mathrm{Si}^{+1}\right)$, (iii) $\mathrm{SiO}\left(\mathrm{Si}^{+2}\right)$, (iv) $\mathrm{Si}_{2} \mathrm{O}_{3}\left(\mathrm{Si}^{+3}\right)$, and (v) the native oxide $\mathrm{SiO}_{2}\left(\mathrm{Si}^{+4}\right)[29,30]$. From the top layers, the elemental $\mathrm{Si} 2 p\left(\mathrm{Si}^{0}\right)$ signal was observed at the exact position of $99.3 \mathrm{eV}$ and this became the dominant mode in the vicinity of the substrate [10,31]. Figure 6(d) shows the peak fit evolutions of some layers and also the table 1 gives the peak fit results of $\operatorname{Si} 2 p$ valence regions of these layers. The intensity of the peaks near $99.3 \mathrm{eV}$, indicating $\mathrm{Si}-\mathrm{Si}$ bonding, increase with the depth as going from the surface to the substrate. The penetration depth of XPS is $5.8 \mathrm{~nm}$ for the $45^{\circ}$ photoelectron take-off angle [32] and the thickness of the examined film was $5.4 \mathrm{~nm}$, Hence, the observed increase in the intensity of the $\mathrm{Si} 2 \mathrm{p}$ photoelectron peaks from top to bottom layers is expected since this peak comes from the substrate. An additional peak of the $\operatorname{Si} 2 p$ emission spectra was found at higher binding energy side relative to $\mathrm{Si}^{0}$. This part of the spectrum was decomposed into two Si photoelectron peaks by a peak fitting process. These two peaks correspond to different oxidation states of silicon as shown in figure 6(d). Figure 6(d) shows one of the sub-peaks seen at all layers which corresponds to the $\mathrm{Hf}-\mathrm{O}-\mathrm{Si}$ bonds reflecting the formation of hafnium silicate $\left(\mathrm{HfSi}_{\mathrm{x}} \mathrm{O}_{\mathrm{y}}\right)$ with a binding energy $\mathrm{BE}=103.2 \mathrm{eV}$ which is then shifted to lower values (from 103.2 to $101 \mathrm{eV}$ ) with the increasing depth $[10,11,33,34]$. Renault et al reported that, when the number the second nearest neighbor Hf atoms of the Si atoms increase in an $\mathrm{Hf}$ silicate film, Si $2 p$ peaks due to the $\mathrm{Hf}$ silicate formation shift to lower binding energies $[12,13]$. Hence we can claim that the second nearest neighbors of Si changes from being mostly Si to being mostly $\mathrm{Hf}$ with the increasing depth. As a result, all layers in the film contain the Hf silicate formation. Figure 6(d) also exhibits two additional peaks which were observed at the first 10 layers in the 103.9-102.5 eV binding energy scale. These peaks correspond either to the native oxide form (fully stoichiometric silica) of silicon, $\mathrm{SiO}_{2}\left(\mathrm{Si}^{4+}\right)$ or $\mathrm{Si}-\mathrm{O}-\mathrm{Si}$ bonding of $\mathrm{Si}[35,36]$. It is noteworthy to say that the intensity the peak due to $\mathrm{Si}^{4+}$ showed a significant reduction after the first 10 layers.

\subsubsection{Hf 4 f depth profile}

$\mathrm{Hf} 4 \mathrm{f}$ spectrum involves the contributions of (i) $\mathrm{Hf}$ metal $\left(\mathrm{Hf}^{0}\right)$, (ii) suboxide form of $\mathrm{HfO}_{2}\left(\mathrm{Hf}^{\mathrm{x}+} \mathrm{O}^{\mathrm{y}}\right)$, and (iii) fully oxidized form of $\mathrm{HfO}_{2}\left(\mathrm{Hf}^{4+} \mathrm{O}^{2-}\right)$ [10,37]. Figure 6(b) shows the all $\mathrm{Hf} 4 f$ spectra obtained from many layers of $\mathrm{HfO}_{2}$ film. Hf $4 f$ core-level spectrum consists of two peaks due to $4 f_{7 / 2}$ and $4 f_{5 / 2}$ energy states that are separated from each other with a spin-orbit splitting value $1.77 \mathrm{eV}$ which is in good agreement with literature [33]. According to our peak fit analysis results as shown in figure 6(e), for the first 10 layers, the film contained one $\mathrm{Hf} 4 f$ doublet. An additional $\mathrm{Hf} 4 \mathrm{fdoublet}$ was observed from 12 th to 18 th layer which is possibly due to different oxidation states of Hf. In figure $6(\mathrm{e}), \mathrm{Hf} 4 f_{7 / 2}$ peak of the first doublet was observed in the first 18 th layers at 17.9 and $18.5 \mathrm{eV}$ binding energy region. These peak positions can be attributed to a fully oxidized hafnium $\mathrm{Hf}^{4+}$ which is an evidence for the formation of hafnium-silicate $\left(\mathrm{HfSi}_{\mathrm{x}} \mathrm{O}_{\mathrm{y}}\right)[10,11,30,38,39]$. Similar results were published by by Fang et al which reported that $\mathrm{HfO}_{2}$ film had a $\mathrm{Hf} 4 f_{7 / 2}$ peak at $16.90 \mathrm{eV}$ with a spinorbit splitting energy of $1.60 \mathrm{eV}$. They observed that towards the deeper layers, these peaks shifted to higher energies (indicating higher binding energies). They observed two different cycles $\mathrm{Hf} 4 f_{7 / 2}$ at $17.45 \mathrm{eV}$ and $18.36 \mathrm{eV}$.

This corresponds to a hafnium silicate formation (Hf-O-Si) located at a higher binding energy, as expected, than that of $\mathrm{HfO}_{2}$ [40]. Wilk et al also reported the binding energy of the $\mathrm{Hf} 4 f_{7 / 2}$ level as $18.30 \mathrm{eV}$ for a thin $\mathrm{Hf}$ silicate film [41]. It can be concluded that, due to the out diffusion of Si or deeper diffusion of oxygen into the substrate caused the formation of $\mathrm{Hf}$ silicate after a period of time on the film growth process.

Since the $\mathrm{Hf}$ silicate, like $\mathrm{HfO}_{2}$, show good electrical properties, high dielectric constant and excellent thermal stability, it has been intensely studied as high-k dielectric gate oxide [19, 37] for MOS and CMOS devices [20]. The combination of $\mathrm{HfO}_{2}$ and $\mathrm{HfSiO}$ structure is called as ' $\mathrm{Hybrid} \mathrm{HfO}_{2}$ film' and is used for metal- 

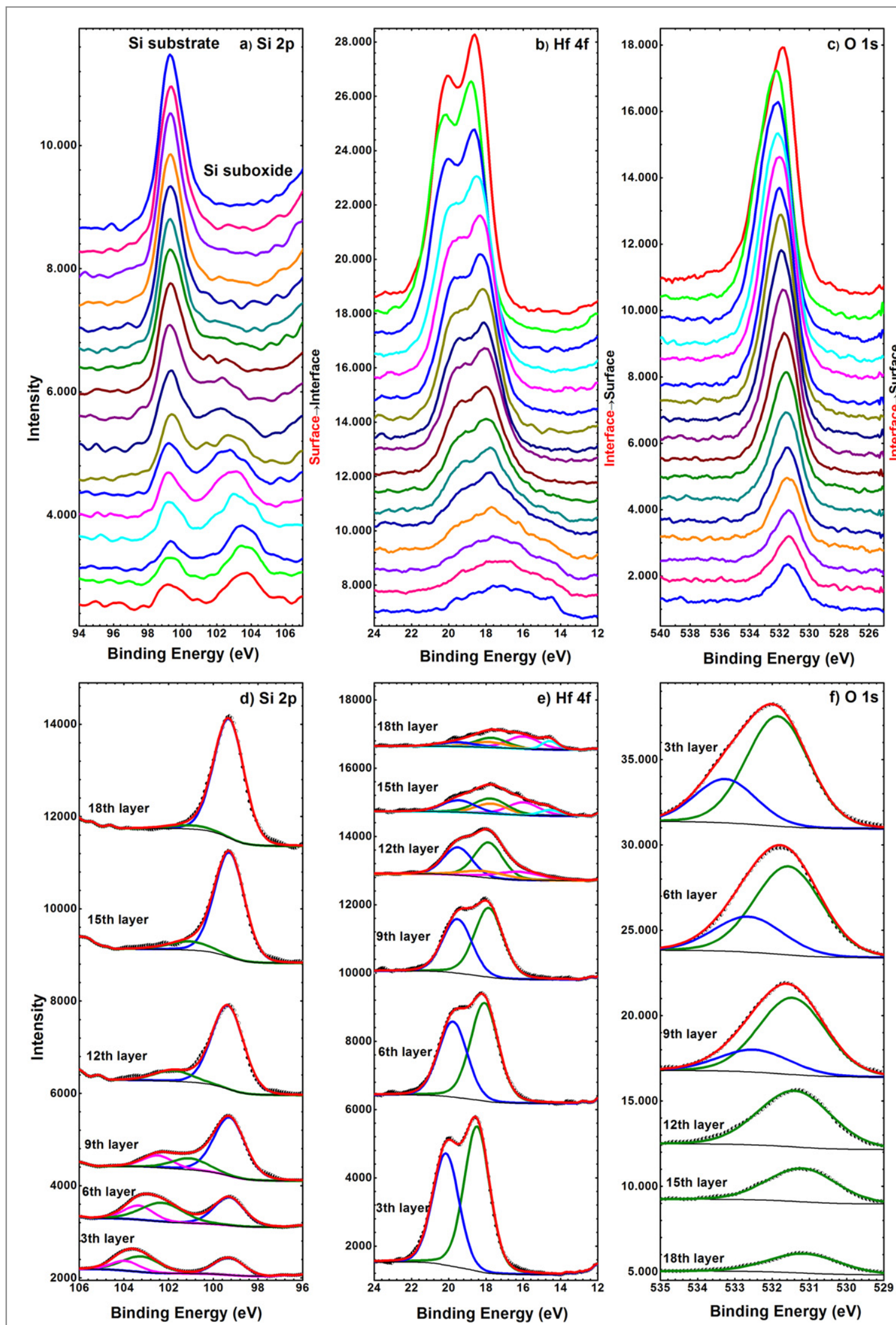

Figure 6. XPS total region depth profile of (a) $\mathrm{Si} 2 p$, (b) $\mathrm{Hf} 4 f$, (c) O 1s spectra and peak fitting results of some layers for (d) Si $2 p$, (e) Hf $4 f$, (f) O $1 s$ spectra.

insulator-semiconductor (MIS) devices. Moreover, the presence of $\mathrm{HfSiO}$ minimize the formation of $\mathrm{SiO}_{2}$ interface layer which is a key requirement for growing a gate oxide stack with high capacitance. In the literature, it has been reported that the formation of Hf-silicate structure also improves the $\mathrm{HfO}_{2} / \mathrm{Si}$ interface [37]. 
Table 1. Peak fit results of $S i 2 p$ valence region of selected layers.

\begin{tabular}{|c|c|c|c|c|c|c|}
\hline Si 2 p region & $\begin{array}{l}\text { BE of 1th } \\
\text { peak }(e V)\end{array}$ & $\begin{array}{l}\text { FWHM of 1th } \\
\text { peak }(\mathrm{eV})\end{array}$ & $\begin{array}{l}\text { BE of 2nd } \\
\text { peak }(e V)\end{array}$ & $\begin{array}{l}\text { FWHM of } 2 \text { nd } \\
\text { peak }(\mathrm{eV})\end{array}$ & $\begin{array}{l}\text { BE of 3th } \\
\text { peak }(e V)\end{array}$ & $\begin{array}{c}\text { FWHM of } 3 \text { th } \\
\text { peak }(\mathrm{eV})\end{array}$ \\
\hline 3th layer & 99.3 & 1.6 & 103.2 & 2.0 & 103.9 & 1.5 \\
\hline 6th layer & 99.3 & 1.6 & 102.2 & 2.2 & 103.3 & 1.5 \\
\hline 9th layer & 99.3 & 1.7 & 101.0 & 2.0 & 102.5 & 1.5 \\
\hline 12th layer & 99.3 & 1.7 & 101.8 & 2.0 & - & - \\
\hline 15th layer & 99.3 & 1.6 & 101.0 & 2.2 & - & - \\
\hline 18th layer & 99.3 & 1.6 & 101.0 & 2.2 & - & - \\
\hline
\end{tabular}
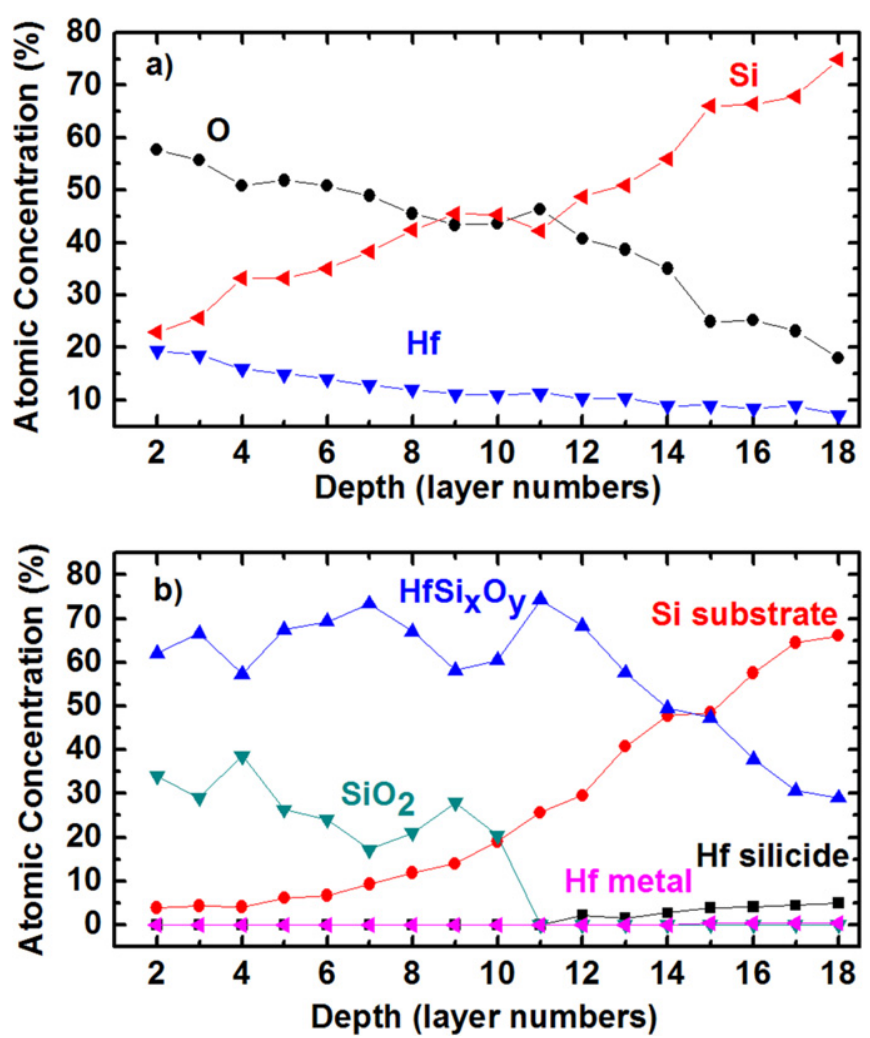

Figure 7. Atomic concentration of (a) constituting elements (b) formed compound with respect to depth of $\mathrm{HfO}_{2}$ film.

Although the $\mathrm{HfSiO}$ formation can not be totally avoided due to the out diffusion of $\mathrm{Si}$, the $\mathrm{SiO}_{2}$ interface formation due to the diffusion of $\mathrm{O}$ was significantly suppressed by $\mathrm{Hf}$ metal buffer layer deposition.

As shown in figure 6(e), in addition to the Hf silicate peak, an extra doublet was appeared at lower binding energies from 12th to the 18th layers, near the Si substrate. This doublet centered at 16.0 and $16.3 \mathrm{eV}$ is due to Hf $4 f_{7 / 2}$ energy state with a spin-orbit splitting energy of $1.77 \mathrm{eV}$. The position of this doublet indicates the existence of Hf-Si (metallic Hf silicide) bonds [36, 42]. Therefore, the Hf silicate is not the only phase formed in the vicinity of bare $\mathrm{Si}$ [36] where $\mathrm{Hf}$ silicide phase also exists. There are two different explanations for the formation process of Hf silicide: The first one was given by Lee et al which said that the silicide was formed in the early stages of the film growth and later it was converted to Hf silicates [39]. The other explanation was due to Jiang et al which stated that $\mathrm{Hf}$ silicate can easily decompose to produce $\mathrm{Hf}$ silicide because of its unstability [43]. The existence of both phases was already reported in earlier studies [44, 45]. Sayan et al carried out detailed investigations on the thermal decomposition of $\mathrm{HfO}_{2} / \mathrm{SiO}_{2} / \mathrm{Si}$ structure [46]. They claimed that, hafnium silicide forms as a result of the reaction of $\mathrm{HfO}_{2}$ with $\mathrm{Si}$ substrate. In the last 4 layers, the metallic $\mathrm{Hf}\left(\mathrm{Hf}^{0}\right)$ peak, observed at $14.5 \mathrm{eV}$, was hardly visible. Since the $\mathrm{Hf}$ silicide and also $\mathrm{Hf}^{0}$ region is limited to the last few layers, $\mathrm{Hf}$ silicate is the dominant phase throughout the film.

\subsubsection{O 1s depth profile}

Figure 6(c) shows the depth profiling with $\mathrm{O} 1 \mathrm{~s}$ spectra, each taken from a different layer. Similar to that of the other elements, the $\mathrm{O} 1 \mathrm{~s}$ valence spectrum obtained from each layer consists of two sub-peaks. One of them, 
which is seen in figure 6(f), is in the range of $531.5-531.8 \mathrm{eV}$ and attributed to $\mathrm{Hf}$ silicate formation [10]. The second one was located in the range 533.2-532.6 eV and related to the oxygen in $\mathrm{SiO}_{2}[10,47]$. The intensity of the oxygen related peak in hafnium silicates was gradually decreased through the depth of the film but not disappeared, indicating that silicate layers were dominated in the film (figure 6(f)).

\subsubsection{Quantitative analysis of $\mathrm{HfO}_{2}$ film by XPS depth profile}

In figures 7(a), (b) the quantification analysis by XPS depth profiling was given. The atomic concentrations of constituted elements (figure 7(a)) for the 2nd layer which was after the surface layer were obtained as $57.69 \%$ for $\mathrm{O}, 19.35 \%$ for $\mathrm{Hf}$, and $22.99 \%$ for $\mathrm{Si}$. In the 18 th layer which was the last layer, the elemental concentrations were found to be $17.98 \%$ for O, 7.13\% for Hf, and 74.89\% for Si. Figure 7(b) shows the atomic concentration of compounds formed inside the $\mathrm{HfO}_{2}$ film. Since the thickness of the film is very close to the penetration depth of the $\mathrm{x}$-rays in XPS, signals from the Si substrate and the interface were also observed in addition to those observed from the surface layer. According to figure 7(b), $\mathrm{Hf}$ silicate is the dominant phase while a broad $\mathrm{SiO}_{2}$ interface layer was formed for the first 10 layers. However, Hf silicate concentration decreases with the layer depth for the deeper layers whereas the concentration of Si substrate increases. After the 12th layer, Hf silicide appears. Since Hf metal was deposited before the film growth process, Hf metal encountered in the last 4 layers exhibit very low atomic concentration in the range of $0.3 \%-0.4 \%$. For the last layer (18th), XPS depth profile shows a $66.10 \% \mathrm{Si}$ concentration from the substrate which means that this layer is very close to the Si substrate.

\section{Conclusion}

In-situ SE and ex situ XPS depth profiling have been comparatively carried out to investigate the phase evolution and interfacial structure of $\mathrm{HfO}_{2} / \mathrm{Hf} / \mathrm{Si}$ layer stack. The sample was prepared by the RF magnetron sputtering technique. In-situ SE results showed that during the reactive oxidation $\mathrm{HfO}_{2}$ film was linearly grown and the first deposited metal $\mathrm{Hf}$ atoms consumed the oxygen of the native $\mathrm{SiO}_{2}$ layer, which disappeared during the deposition, to form $\mathrm{HfO}_{2}$. SE measurements taken after reactive oxidation were revealed the formation of $\mathrm{SiO}_{2}$ interface due to diffusion of oxygen towards the $\mathrm{Si}$ substrate and the increase in the Si concentration in $\mathrm{HfO}_{2}$ film due to the out diffusion of $\mathrm{Si}$ which was supported by reduction in refractive index. The existence of $\mathrm{SiO}_{2}$ interface layer was also confirmed from the FTIR analysis. The evolution in the phase of $\mathrm{HfO}_{2}$ film was cross checked by XPS depth profiling analysis. XPS results verified the out diffusion of Si which resulted the $\mathrm{HfO}_{2}$ film with an Hf silicate rich structure. The diffusion of oxygen was also confirmed by XPS that resulted the formation of $\mathrm{SiO}_{2}$ interface layer again. Intentionally deposited $\mathrm{Hf}$ layer suppressed the oxygen diffusion so, the only $2 \mathrm{~nm}$ thick $\mathrm{SiO}_{2}$ interface layer was formed which was thinner than naturally formed $\mathrm{SiO}_{2}$. In the vicinity of $\mathrm{Si}$ substrate, a lower amount of $\mathrm{Hf}$ silicate was reported where only a few layers had $\mathrm{Hf}$ silicide and metallic $\mathrm{Hf}^{0}$. Thanks to the comparison of in situ SE and ex situ XPS results, the phase evolution of $\mathrm{HfO}_{2}$ film grown on a Hf/ Si substrate was investigated in detail.

\section{Acknowledgments}

This study was supported by The Scientific and Technological Research Council of Turkey (TUBITAK) project (\# 113F349). XPS measurements were done in 'Applied Quantum Research Center' in Izmir Institute of Technology.

\section{ORCID iDs}

Ayten Cantas (iD) https://orcid.org/0000-0002-6536-5516

Gulnur Aygun (10 https://orcid.org/0000-0003-0860-2914

\section{References}

[1] Mroczyński R, Kalisz M and Dominik M 2016 Electrical characterization of MIS structures with $\mathrm{HfO}_{\mathrm{x}}$ gate dielectric films fabricated on silicon substrates modified by ultra-shallow ion implantation from RF plasma Phys. Status Solidi C 13 1-6

[2] Manikanthababu N, Chan T K, Vajandar S, Saikiran V, Pathak A P, Osipowicz T and Nageswara Rao S V S 2017 Ion induced intermixing and consequent effects on the leakage currents in $\mathrm{HfO}_{2} / \mathrm{SiO}_{2} / \mathrm{Si}$ systems Appl. Phys. A 123303

[3] Xu D-P, Yu L-J, Chen X-D, Chen L, Sun Q-Q, Zhu H, Lu H-L, Zhou P, Ding S-J and Zhang D W 2017 In situ analysis of oxygen vacancies and band alignment in $\mathrm{HfO}_{2}$ /TiN structure for CMOS applications Nanoscale Res. Lett. 12311

[4] Nath M and Roy A 2016 Interface and electrical properties of ultra-thin $\mathrm{HfO}_{2}$ film grown by radio frequency sputtering Physica B 482 43-50 
[5] Salomone L S, Lipovetzky J, Carbonetto S H, García Inza M A, Redin E G, Campabadal F and Faigón A 2016 Deep electron traps in $\mathrm{HfO}_{2}$-based metal-oxide-semiconductor capacitors Thin Solid Films $60036-42$

[6] Vlček J, Belosludtsev A, Rezek J, Houška J, Čapek J, Čerstvý R and Haviar S 2016 High-rate reactive high-power impulse magnetron sputtering of hard and optically transparent $\mathrm{HfO}_{2}$ films Surf. Coat. Technol. 290 58-64

[7] He G, Zhang L D, Li G H, Liu M, Zhu L Q, Pan S S and Fang Q 2005 Spectroscopic ellipsometry characterization of nitrogenincorporated $\mathrm{HfO}_{2}$ gate dielectrics grown by radio-frequency reactive sputtering Appl. Phys. Lett. 86232901

[8] Robertson J 2006 High dielectric constant gate oxides for metal oxide Si transistor Rep. Prog. Phys. 69327-96

[9] Wilk G D, Wallace R M and Anthony J M 2001 High-k gate dielectrics: current status and materials properties considerations J. Appl. Phys. 89 5243-75

[10] Aygun G and Yildiz I 2009 Interfacial and structural properties of sputtered $\mathrm{HfO}_{2}$ layers J. Appl. Phys. 106014312

[11] Tan R, Azuma Y and Kojima I 2005 X-Ray photoelectron spectroscopic analysis of $\mathrm{HfO}_{2} / \mathrm{Hf} / \mathrm{SiO} \mathrm{O}_{2} / \mathrm{Si}$ structure Appl. Surf. Sci. 241 $135-40$

[12] Tan R Q, Azuma Y, Fujimoto T, Fan J W and Kojima I 2004 Preparation of ultrathin $\mathrm{HfO}_{2}$ films and comparison of $\mathrm{HfO}_{2} / \mathrm{SiO} 2 / \mathrm{Si}$ interfacial structures Surf. Interface Anal. $361007-10$

[13] Renault O, Samour D, Damlencourt J-F, Blin D, Martin F and Marthon S $2002 \mathrm{HfO}_{2} / \mathrm{SiO}_{2}$ interface chemistry studied by synchrotron radiation X-ray photoelectron spectroscopy Appl. Phys. Lett. 81 3627-9

[14] Cantas A, Aygun G and Basa D K 2014 In-situ spectroscopic ellipsometry and structural study of $\mathrm{HfO}_{2}$ thin films deposited by radio frequency magnetron sputtering J. Appl. Phys. 116083517

[15] Fujiwara H 2007 Spectroscopic Ellipsometry: Principles and Applications (New York: Wiley)

[16] Buldu D G, Cantas A, Turkoglu F, Akca F G, Meric E, Ozdemir M, Tarhan E, Ozyuzer L and Aygun G 2018 Influence of sulfurization temperature on $\mathrm{Cu}_{2} \mathrm{ZnSnS}_{4}$ absorber layer on flexible titanium substrates for thin film solar cells Phys. Scr. 93024002

[17] Yazici S, Olgar M A, Akca F G, Cantas A, Kurt M, Aygun G, Tarhan E, Yanmaz E and Ozyuzer L 2015 Thin Solid Films 589 563-73

[18] Cantas A, Turkoglu F, Meric E, Akca F G, Ozdemir M, Tarhan E, Ozyuzer L and Aygun G 2018 J. Phys. D: Appl. Phys. 51275501

[19] Yang W, Fronk M, Geng Y, Chen L, Sun Q-Q, Gordan O D, Zhou P, Zahn D R T and Zhang D W 2015 Optical properties and bandgap evolution of ALD HfSiO films Nanoscale Res. Lett. 1032

[20] Mitrovic I Z, Buiu O, Hall S, Bungey C, Wagner T, Davey W and Lu Y 2007 Electrical and structural properties of hafnium silicate thin films Microelectron. Reliab. 47 645-8

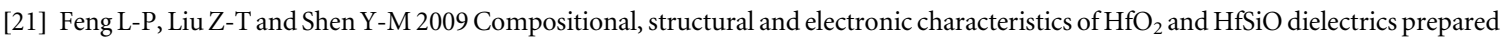
by radio frequency magnetron sputtering Vacuum $83902-5$

[22] Patterson A L 1939 The scherrer formula for x-ray particle size determination Phys. Rev. 56 978-82

[23] Wang Z-J, Kumagai T, Kokawa H, Tsuaur J, Ichiki M and Maeda R 2005 Crystalline phases, microstructures and electrical properties of hafnium oxide films deposited by sol-gel method J. Cryst. Growth $281452-7$

[24] Bordo Kand Rubahn H G 2012 Effect of deposition rate on structure and surface morphology of thin evaporated Al films on dielectrics and semiconductors Mater. Sci. 18313-7

[25] Kim P, Moon S-J and Jeong S 2011 Effects of irradiation conditions on the lateral grain growth during laser crystallization of amorphous silicon films on borosilicate glass substrates Appl. Phys. A-Mater. 104 851-5

[26] Neumayer D A and Cartier E 2001 Materials characterization of $\mathrm{ZrO}_{2}-\mathrm{SiO}_{2}$ and $\mathrm{HfO}_{2}-\mathrm{SiO}_{2}$ binary oxides deposited by chemical solution deposition J. Appl. Phys. 90 1801-8

[27] Houssa M, Pantisano L, Ragnarsson L A, Degraeve R, Schram T, Pourtois G, De Gendt S, Groeseneken G and Heyns M M 2006 Electrical properties of high-k gate dielectrics: Challenges, current issues, and possible solutions Mat. Sci. Eng., R 51 37-85

[28] Toledano-Luque M, San Andrés E, del Prado A, Mártil I, Lucía M L and González-Díaz G 2007 High-pressure reactively sputtered $\mathrm{HfO}_{2}$ : composition, morphology, and optical properties J. Appl. Phys. 102044106

[29] Aygun G, Atanassova E, Alacakir A, Ozyuzer L and Turan R 2004 Oxidation of Si surface by a pulsed Nd:YAG laser J. Phys. D: Appl. Phys. 37 1569-75

[30] Maunoury Cet al 2007 Chemical interface analysis of as grown $\mathrm{HfO}_{2}$ ultrathin films on $\mathrm{SiO}_{2}$ J. Appl. Phys. 101034112

[31] Yakovkina L V, Kichai V N, Smirnova T P, Kaichev V V, Shubin Y V, Morozova K V and Igumenov I K 2005 Preparation and properties of Thin $\mathrm{HfO}_{2}$ films Inorg. Mater. 41 1300-4

[32] Liu J, Lennard W N, Goncharova L V, Landheer D, Wu X, Rushworth S A and Jones A C 2009 Atomic layer deposition of hafnium silicate thin films using tetrakis (diethylamido) hafnium and Tris (2-methyl-2-butoxy) silanol J. Electrochem. Soc. 156 G89-96

[33] Sokolov A A, Filatova E O, Afanasev V V, Taracheva EY, Brzhezinskaya M M and Ovchinnikov A A 2009 Interface analysis of $\mathrm{HfO}_{2}$ films on (100) Si using X-ray photoelectron spectroscopy J. Phys. D: Appl. Phys. 42 1-6

[34] Zhu Y Y, Fang Z B, Liao C, Chen S and Jiang Z M 2008 In situ photoemission study on initial growth of $\mathrm{Er}_{2} \mathrm{O}_{3}$ films on Si (001) Key Eng. Mat. 373-374 625-8

[35] Rudenja S, Minko A and Buchanan D A Low-temperature deposition of stoichiometric $\mathrm{HfO}_{2}$ on silicon: analysis and quantification of the $\mathrm{HfO}_{2} / \mathrm{Si}$ interface from electrical and XPS measurements Appl. Surf. Sci. 257 17-21

[36] Sahin D, Yildiz I, Gencer A I, Aygun G, Slaoui A and Turan R 2010 Evolution of $\mathrm{SiO}_{2} / \mathrm{Ge} / \mathrm{HfO}_{2}(\mathrm{Ge})$ multilayer structure during high temperature annealing Thin Solid Films $5182365-9$

[37] Lin C-W, Zheng B-S and Huang J-W 2016 Formation of hybrid hafnium oxide by applying sacrificial silicon film Jpn. J. Appl. Phys. 55 $01 \mathrm{AA} 10$

[38] Suzer S, Sayan S, Garfunkel E, Hussain Z and Hamdan N M 2002 Soft x-ray photoemission studies of Hf oxidation J. Vac. Sci. Technol. A $21106-9$

[39] Lee P F, Dai J Y, Chan H L W and Choy C L 2004 Two-step interfacial reaction of $\mathrm{HfO}_{2}$ high-k gate dielectric thin films on Si Ceram. Int. $301267-70$

[40] Fang Q et al 2004 Interface of ultrathin HfO films deposited by UV-photo-CVD Thin Solid Films 453-454 203-7

[41] Wilk G D, Wallace R M and Anthony J M 2000 Hafnium and zirconium silicates for advanced gate dielectrics J. Appl. Phys. 87 484-92

[42] Kato H, Nango T, Miyagawa T, Katagiri T, Seol K S and Ohki Y 2002 Plasma-enhanced chemical vapor deposition and characterization of high-permittivity hafnium and zirconium silicate films J. Appl. Phys. 92 1106-11

[43] Jiang R and Li Z-F 2009 Oxygen recovery in Hf oxide films fabricated by sputtering Chin. Phys. Lett. 26057101

[44] Smirnova T P, Kaichev V V, Yakovkina L V, Kosyakov V I, Beloshapkin S A, Kuznetsov F A, Lebedev M S and Gritsenko V A 2008 Composition and structure of hafnia films on silicon Inorg. Mater. 44 965-70

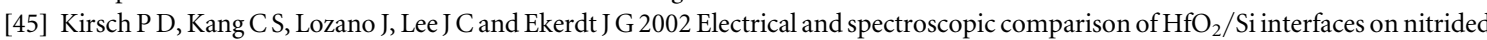
and un-nitrided Si (100) J. Appl. Phys. 91 4353-63 
[46] Sayan S, Garfunkel E, Nishimura T, Schulte W H, Gustafsson T and Wilk G D 2003 Thermal decomposition behavior of the $\mathrm{HfO}_{2} / \mathrm{SiO}_{2} / \mathrm{Si}$ system J. Appl. Phys. $94928-34$

[47] Rangarajan V, Bhandari H and Klein T M 2002 Comparison of hafnium silicate thin films on silicon ( 100$)$ deposited using thermal and plasma enhanced metal organic chemical vapor deposition Thin Solid Films 419 1-4 